\title{
GIANFRANCO MAGLIO, Il mondo di Dante e la povertà evangelica. Padova, Wolters Kluver - CEDAM, 2018, 235 pp., ISBN: 9788813365196
}

Este último libro de Gianfranco Maglio, dedicado de nuevo de Dante, se ocupa en realidad del «mundo de Dante», que el autor sintetiza en el gran debate sobre la pobreza evangélica, que se desarrolla desde el tercer decenio del siglo XIII hasta los años treinta o cuarenta del siglo XIII. La pobreza evangélica es asumida por el autor como la llave maestra para reconstruir la formación y la evolución de los principales aspectos intelectuales, religiosos y políticos que conformaron el «mundo de Dante».

Los capítulos centrales del libro analizan, por una parte, el valor de la pobreza en la obra de Dante, partiendo de su propia experiencia de desposesión y exilio, y la dignidad de la pobreza evangélica (capítulo II); y por otra, la pobreza de la Iglesia en el pensamiento político y religioso del poeta florentino, siguiendo las críticas que realiza de la «Donación de Constantino» en la Monarquía, las diatribas por la decadencia de la Iglesia en la Divina Comedia y la apelación a la pobreza eclesiástica que realiza en la Epistola XI (capítulo III).

En la reflexión dantesca hay una doble vertiente de la pobreza: como virtud individual o itinerario personal para la difícilmente realizable perfección de todo cristiano y como el único camino posible y obligado para la iglesia y sus ministros. Desde la perspectiva individual, Dante critica la avaricia y la codicia y destaca que el sentido profundo de la libertad humana exige reducir al máximo la libido possidendi. De acuerdo con la dignidad de la pobreza evangélica, que Dante interpreta a partir de la experiencia franciscana, invita a un proceso de purificación, porque recuperar la plena humanidad significa liberarse de todo lo que nos liga demasiado a la tierra, liberarse de los bienes materiales y de las riquezas. Sin embargo, Dante, lejos el radicalismo de los espirituales y más crcano al «justo medio» aristotélico guiado por la razón, excluye de la vida personal los excesos y concibe la pobreza más como equilibrio, sobriedad y autonomía. Emerge así también la pobreza como valor cívico universal, al modo del estoicismo romano, y no solo como itinerario de perfección cristiana, según el mensaje de san Francisco.

Desde la perspectiva institucional, Dante critica la decadencia moral del clero, de las órdenes religiosas y de la Iglesia y mantiene con mucha firmeza que la pobreza evangélica es condición neesaria para quienes abracen los votos religiosos o se dediquen a la predicación del Evangelio y a la administración de los sacramentos. Pero tampoco se le puede atribuir al poeta una posición extremista como la de Ubertino de Casale, ni siquiera como la de Marsilio de Padua. Dante es radical en pretender que la Iglesia renuncie al poder temporal, en todas las formas y privilegios, quiere que el clero sea pobre, antes que nada «en espíritu». Pero no exige una pobreza extrema, sino que concede la conveniencia de contar con bienes necesarios para la misión religiosa y la posibilidad de disponer de bienes para ejercer la caridad.

Esos dos capítulos sobre el significado de la pobreza en Dante, constituyen el núcleo central del libro. Viene precedido por un primer capítulo, que explica el ideal franciscano y las diversas interpretaciones y enfrentamientos a que dio lugar la pobreza franciscana. Y va seguido por otro (capítulo IV), que analiza la influencia de la concepción de la pobreza eclesiástica en la lucha política entre los dos poderes, mediante las obras de Marsilio de Padua y Guillermo de Ockham.

Cierra el libro un largo capítulo de conclusiones críticas sobre la pobreza evangélica y la espiritualidad medieval. Parte de la convición de que la revolución franciscana propone la imitación y el seguimiento de Cristo como una opción de vida no solo para los clerigos sino también para los laicos. Al final se pregunta y trata de responder tres preguntas: cuál fue el impacto de la discusión sobre la pobreza en los equilibrios políticos del mundo de Dante; en qué modo la espiritualidad medieval salió enriquecida de esos debates; y hasta qué punto tuvo éxito el sueño de san Francisco de un mundo purificado por el amor evangélico.

BERNARDO BAYONA AZNAR Universidad de Zaragoza 